\title{
A atual Fazenda do Arado em Porto Alegre: um campo de batalha entre a especulação capitalista e a construção coletiva da paisagem.
}

L'actuelle Fazenda do Arado à Porto Alegre : un champ de bataille entre la spéculation capitaliste et la construction collective du paysage.

La actual Fazenda do Arado en Porto Alegre: un campo de batalla entre la especulación capitalista y la construcción colectiva de la paisaje.

The Fazenda do Arado in Porto Alegre of today: a battlefield between capitalist speculation and the collective construction of the landscape.

\section{Juan Guillermo Villegas.}

\section{(2) OpenEdition}

Journals

Edição electrónica

URL: http://journals.openedition.org/espacoeconomia/5905

DOI: $10.4000 /$ espacoeconomia.5905

ISSN: 2317-7837

Editora

Núcleo de Pesquisa Espaço \& Economia

Refêrencia eletrónica

Juan Guillermo Villegas., "A atual Fazenda do Arado em Porto Alegre: um campo de batalha entre a especulação capitalista e a construção coletiva da paisagem. », Espaço e Economia [Online], 14 | 2019, posto online no dia 12 agosto 2019, consultado o 06 setembro 2019. URL : http://

journals.openedition.org/espacoeconomia/5905; DOI : 10.4000/espacoeconomia.5905

Este documento foi criado de forma automática no dia 6 Setembro 2019.

(C) NUPEE 


\title{
A atual Fazenda do Arado em Porto Alegre: um campo de batalha entre a especulação capitalista e a construção coletiva da paisagem.
}

\author{
L'actuelle Fazenda do Arado à Porto Alegre : un champ de bataille entre la \\ spéculation capitaliste et la construction collective du paysage. \\ La actual Fazenda do Arado en Porto Alegre: un campo de batalla entre la \\ especulación capitalista y la construcción colectiva de la paisaje. \\ The Fazenda do Arado in Porto Alegre of today: a battlefield between capitalist \\ speculation and the collective construction of the landscape.
}

Juan Guillermo Villegas.

\section{Introdução}

1 Este artigo desenvolve-se a partir da seguinte tese: os empreendimentos na Fazenda do Arado (Bairro Belém Novo, Porto Alegre) apresentam uma luta pela exploração de uma paisagem periférica vulnerável pelas suas características naturais, seguindo as tendências atuais das cidades para a ampliação dos limites urbanos e para a utilização especulativa da paisagem, produzindo essas lutas pela urbanização das áreas rurais. A contraposição da proposta dos empreendimentos diante da realidade corroborada pela história e pelos fatos permitiria construir um conceito de paisagem local, a partir de uma visão coletiva e participativa, técnica e transdisciplinar.

o que aparentemente acontece é a exploração especulativa da paisagem da Fazenda do Arado através de empreendimentos próprios das tendências da urbanização capitalista. Os grandes grupos econômicos realizam pressão para modificar os usos do solo e obter mais solo urbano, tornando-se gestores da paisagem e gerando impactos em entornos vulneráveis. Acredita-se que o que deveria acontecer é a construção coletiva da paisagem 
da Fazenda como parte do bairro e da cidade, na qual o Estado, desde uma qualificação sociocultural do território, deve garantir que os usos do solo sejam os mais convenientes para a cidadania, limitando a influência dos grandes capitais e protegendo as riquezas naturais através da adequada gestão da paisagem.

A abordagem é o estudo da paisagem da Fazenda do Arado através de uma metodologia descritiva, associativa e propositiva, onde primeiro se caracteriza a problemática atual, depois se associa com o viés da urbanização capitalista para a utilização especulativa da paisagem e finalmente se contrapõe à construção do conceito de paisagem local. 0 estudo está enquadrado dentro de uma pesquisa maior que procura instrumentos para analisar o potencial de desenvolvimento intraurbano das cidades, isto é, gerar estratégias de adensamento e compacidade para frear o crescimento expansivo e a periferização próprios do rumo atual do desenvolvimento urbano. Este rumo está baseado em um suposto "esgotamento do solo urbano", que é a escusa da urbanização capitalista. Por esta razão a abordagem tem relevância no caso apresentado, entendendo que a Fazenda do Arado faz parte da periferia de Porto Alegre.

O texto apresenta a seguinte estrutura: primeiro se expõem as definições utilizadas (paisagem e gestão da paisagem): as regras do jogo. Posteriormente se realiza uma análise seletiva e sintética para caracterizar a paisagem da Fazenda -o campo de batalhautilizando uma ordem que se define desde o início. Depois se associa o problema com as tendências constitutivas das metrópoles latino-americanas, desvendando a utilização especulativa da paisagem como "arma" da urbanização capitalista. Finalmente se contrapõem os fatos rodeando o conceito de paisagem local que vai ligado à realidade técnica e à participação social e que se apresenta como mecanismo de defesa para equilibrar a luta.

De maneira geral o artigo visa analisar os empreendimentos da Fazenda do Arado no marco das tendências do desenvolvimento das cidades, para desvendar a paisagem como fonte de especulação e sugerir olhares alternativos. Nesta trilha inicialmente se propõe caracterizar a paisagem da Fazenda desde condições como a vulnerabilidade do entorno natural, os componentes da paisagem, a variação normativa, a localização dos usos propostos e as resistências dos moradores locais. Posteriormente busca-se associar o projeto da Fazenda do Arado com a tendência para a ampliação das fronteiras urbanas, fazendo ênfase na utilização da paisagem como fonte da especulação capitalista. Finalmente o artigo visa contrapor a paisagem especulativa à noção de paisagem local, através de elementos teóricos que desde uma abordagem coletiva $\mathrm{e}$ transdisciplinar permitam encarar a luta encontrada.

\section{A paisagem da fazenda do Arado, descrição do "campo de batalha"}

7 A paisagem é objeto de estudo de várias disciplinas e, em consequência, existem também diversas abordagens do conceito. Por essa razão, é importante esclarecer quais são as definições aqui utilizadas. A principal referência é o Convênio Europeu da Paisagem (CEP) porque embora é uma referência estrangeira; recolhe objetivos comuns dos países participantes; está baseado em documentos legais a nível internacional ${ }^{1}$ e tem um âmbito de aplicação geral no território, abrangendo as áreas naturais, rurais, urbanas e 
periurbanas. O CEP (2000) oferece e está baseado nas definições de paisagem, gestão das paisagens, políticas nos assuntos de paisagens, objetivo de qualidade paisagística, proteção das paisagens e ordenação paisagística. Inicialmente interessam as duas primeiras, transcritas a continuação:

Por "paisagem" se entenderá qualquer parte do território tal como é percebida pela população, cujo carácter seja o resultado da ação e interação de fatores naturais e/ou humanos.

Por "gestão das paisagens" se entenderão as ações encaminhadas, desde uma perspectiva de desenvolvimento sustentável, para garantir a manutenção regular de uma paisagem, com o fim de guiar e harmonizar as transformações induzidas pelos processos sociais, econômicos e meio ambientais.

10 Este artigo apropria-se da estrutura proposta por Busquets e Cortina (2009) em relação à fase de "Conhecimento e diagnose" dentro da "Gestão da paisagem como processo". Para esta fase, reconhecida como fundamental, os autores propõem uma análise em diferentes partes, assim: a) Análise territorial, que descreve os componentes locacionais, geomorfológicos, biofísicos e socioeconômicos; b) Diagnose da paisagem, relacionada com os componentes visuais, perceptivos, culturais, ecogeográficos e o estado atual e as tendências; c) Análise das fontes de informação, direta e indireta; e d) O papel dos atores sociais e institucionais. Os temas se apresentam em forma de sumário síntese sobre a diagnose.

\section{a) Análise territorial:}

Figura 1- Localização geral. Porto Alegre no Brasil e a Fazenda do Arado em Porto Alegre.

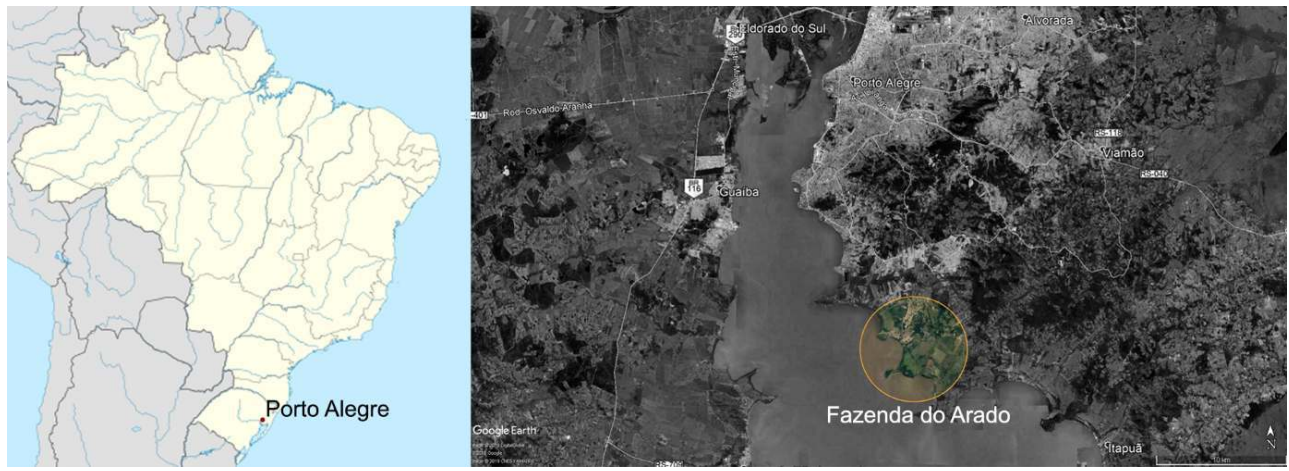

Fonte: Elaboração do autor sobre mapas de Wikipédia e Google Earth.

11 A Fazenda do Arado é um território rodeado em grande parte pelo Lago Guaíba, que engloba uma área de 426 hectares, localizado no Extremo-Sul de Porto Alegre (Ver Figura 1), entre os bairros Belém Novo e Lami. A principal via de acesso desde o centro da cidade é a Avenida Juca Batista que conecta com Belém Novo e posteriormente com a Avenida do Lami que é o limite norte da Fazenda. No lado leste, a Fazenda limita com um cultivo de soja, enquanto nos lados sul e na maior parte do lado oeste limita com o Lago Guaíba. A parte restante do lado oeste limita com Belém Novo que está conectado com a Fazenda através da Avenida Heitor Viêira (Ver Figura 2). 
Figura 2 - Localização específica.

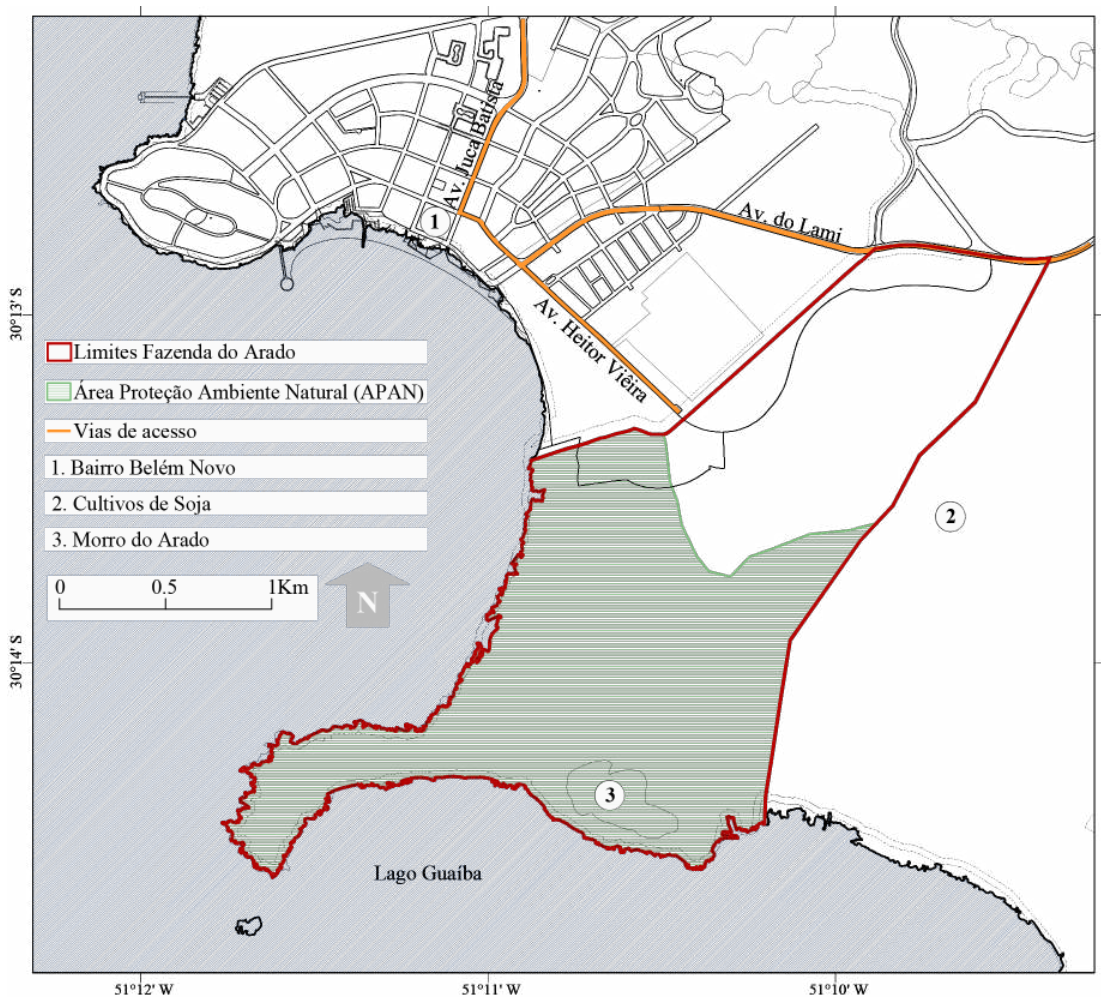

Fonte: Elaboração do autor sobre plano da Secretaria de Urbanismo Porto Alegre. Sistema Geográfico de referência SIRGAS 2000 UTM 22S, 2018

A geomorfologia da Fazenda pode-se resumir em Oliveira (2017) assim:

A parte zoneada como Área de Preservação do Ambiente Natural (APAN) da Fazenda (Ver Figura 2) corresponde exatamente ao terraço lacustre mais recente: os cordões arenosos do chamado Sistema Laguna-Barreira. O relevo da área da Fazenda apresentaria duas conformações distintas com uma ampla superfície de solo arenoso, baixa, plana e alagadiça, tradicionalmente utilizada para o plantio de arroz; e dois promontórios graníticos, isto é, o pequeno morro à Oeste e o Morro do Arado com cerca de 61 metros acima da linha d'água. (MENEGAT, 2016, apud OLIVEIRA, 2017, p.32)

Os componentes biofísicos estão baseados nos Estudos de Impacto Ambiental (EIA) (PROFILL, 2013a) dos empreendimentos em questão e em documentos do movimento "Preserva Arado". Grande parte da Fazenda está composta por campos de várzea com maricazais e banhados (permanentes e sazonais). Como é típico dos ecossistemas de restinga da planície costeira do estado, tem fragmentos de mata atlântica, que apresentam-se também de maneira mais densa na Ponta e no Morro do Arado. A orla está formada por praias de areia intercaladas com juncais e aguapés. Segundo o Relatório de Impacto Ambiental - RIMA - (PROFILL, 2013c), na Fazenda foram identificadas 8 espécies de anfíbios, 13 de répteis, 142 de aves e 13 de mamíferos. 0 número de espécies de aves representa o $21 \%$ da avifauna presente no Estado e o $84 \%$ do total de espécies de aves que podem ser geralmente registradas em Porto Alegre, algumas delas com status de "perigo de extinção"2.

No aspecto socioeconômico, Oliveira (2017) relata que a Fazenda foi adquirida no início do século XX pelo jornalista Breno Caldas (1910 - 1989), quem instalou um centro de criação 
de cavalos. Hoje, a área é propriedade de um grupo empresarial que tem proposto o "Empreendimento Urbanístico Arado Velho". Na Fazenda existem algumas estruturas construídas que ficam nas regiões planas enquanto outras estruturas mais recentes localizam-se sobre o Morro do Arado. As atividades desenvolvidas relacionam-se com agropastoris para produção de leite, arroz e ainda hoje à criação de cavalos de corrida. Os elementos construídos são conectados por antigas estradas mal conservadas.

\section{b) Diagnose da paisagem:}

Em relação aos componentes visuais trata-se de uma paisagem com tendência à horizontalidade determinada pelo encontro do lago e o céu. Sendo uma área plana e de cotas baixas, as perspectivas são abertas e as superfícies homogéneas. Desde o bairro, nos primeiros planos destacam-se árvores de grande altura na orla do lago, enquanto nos planos de fundo sobressaem alguns morros de pouca altura que não interferem na horizontalidade. A pouca quantidade de elementos construídos e a ausência de acidentes naturais gera um cromatismo básico, de poucas sombras e muita luz. A parte sul da Fazenda é uma península que entra no Guaíba e gera uma bacia visual sem barreiras, que determina o principal componente perceptivo pois permite olhar desde a Fazenda para o bairro e vice-versa (Ver Figura 2).

componentes culturais da Fazenda, sua história e tradições, têm a ver com a formação do bairro. O povoamento se deu na forma de chácaras de produção agrícola que comerciavam com outras localidades através de um porto e vários trapiches (OLIVEIRA, 2017). Nas primeiras décadas do século $X X$ o bairro adquiriu a função de balneário $e$ recebeu um desenvolvimento urbanístico que colocou na paisagem restaurantes, um hotel e várias casas de veraneio. Hoje o bairro tem características muito típicas que se descrevem em palavras de um morador local: "Temos costumes interioranos. Por aqui se percebem as crianças nas praças, domingo de missa e cavalos pelas ruas" (OLIVEIRA, 2017, p. 46).

17 Dentro dos componentes ecogeográficos, é possível caracterizar ao menos três unidades de paisagem: $O$ bairro, a Fazenda e a orla. $O$ bairro, tendo em conta a densidade, a distância até o centro de Porto Alegre e a presença do lago; se apresenta como uma unidade rururbana. A fazenda, com poucas estruturas construídas, com "cerca da metade da área como Área de Proteção do Ambiente Natural (APAN)" (OLIVEIRA, 2017, p.44) e sendo um terreno altamente sujeito às inundações; obtém o caráter de unidade rural. Este caráter vem reforçado pela proximidade de várias Unidades de Conservação protegidas por lei, pois "as áreas de várzeas e banhados que localizam-se fora de Unidades de Conservação têm a função de corredores ecológicos para a fauna, sobretudo de aves e mamíferos" (DOSSIÉ, 2016, apud OLIVEIRA, 2017, p.45). Finalmente, a orla apresenta-se como uma unidade de paisagem comum às anteriores, com caráter próprio pela presença do lago, mas que recebe características das outras duas unidades, sendo em consequência tanto rururbana quanto rural.

18 A soma dos componentes permite perceber que o estado atual da Fazenda está caracterizado pela presença de grandes valores paisagísticos, embora as dinâmicas evolutivas (próprias de uma região que faz parte de uma área metropolitana da escala de Porto Alegre) tenham gerado mudanças nas formas de vida tradicionais. A principal tendência, ao menos pelas aparências da problemática percebida, visa a realização de um 
grande empreendimento urbanístico que mudaria consideravelmente as condições atuais, isto é, a geraria impactos diretos nos âmbitos natural, social e cultural.

\section{c) Análise das fontes de informação:}

19 "A primeira fonte de informação direta é o próprio território e o trabalho de campo de estudo da paisagem realizado in situ" (BUSQUETS e CORTINA, 2009, p15). Por isso se realizaram várias visitas que permitiram obter dados sobre diversas variáveis, verificar a informação prévia e contrastar os conceitos iniciais diante das percepções próprias da área de estudo. Os principais produtos foram desenhos e fotografias da paisagem do bairro visto desde a fazenda nos quais se obtiveram imagens que abrangem grande parte do território e confirmam as percepções de horizontalidade e à predominância dos elementos naturais. Desde a Fazenda, a estrutura urbana do bairro é praticamente imperceptível e por isso o trabalho de campo gerou questionamentos relacionados com a ausência de anúncios normativos ou publicitários que oferecessem informação sobre o empreendimento.

Com relação à informação indireta, os aspectos mais relevantes são de caráter normativo. Maroneze (2017) narra que no curso dos últimos 40 anos, a definição dos usos do solo na região tem estado mudando consideravelmente, até o ponto de tornar-se um objeto complexo de estudo e discussão entre os diferentes atores. Em 1979, segundo o Plano Diretor de Desenvolvimento Urbano (PDDU) a cidade estava dividida em Zona Urbana e Zona Rural, estando a região da Fazenda do Arado dentro da Zona Rural. Em 1999, e segundo o Plano Diretor de Desenvolvimento Urbano Ambiental (PDDUA), a cidade não teve mais Zona Rural e em consequência, a região onde encontra-se a Fazenda ficou dentro de uma área conhecida como "Macrozona 8" e adquiriu o caráter de "Cidade Rururbana". Vários anos depois, no mês de setembro de 2015, a Secretaria Municipal de Urbanismo (SMURB) restituiu a Zona Rural de Porto Alegre e assim a Fazenda recuperou sua denominação rural.

21 De maneira inesperada, o mês de novembro de 2015, a Prefeitura Municipal de Porto Alegre (PMPA) através de uma decisão da câmara de vereadores, reduziu a Zona Rural recém demarcada justamente na região da Fazenda do Arado, possibilitando assim o empreendimento previsto. Naquele momento e como requisito, os responsáveis do empreendimento aceitaram a realização de uma série de contrapartidas "acordadas" forma rápida como mudou a demarcação da Zona Rural gerou o descontentamento da cidadania e por isso entre o final de 2015 e durante 2016 foram apresentados vários inquéritos civis com o objetivo de esclarecer a situação. 0 resultado foi que no mês de abril de 2017, o Ministério Público Estadual reconheceu vício na Lei emitida pela câmara em 2015 e que tinha reduzido a área rural. Por isso o aspecto normativo se percebe como complexo, justificando a definição da presente descrição como "campo de batalha".

\section{d) O papel dos atores sociais e institucionais:}

Consideram-se quatro atores determinantes: Os empreendedores, os coletivos ambientalistas, a população do bairro Belém Novo e o Estado.

Os empreendedores: Na Fazenda do Arado, a empresa Arado Empreendimento LTDA tem proposto um desenvolvimento urbanístico de grande escala e, para atender os Termos de Referência exigidos, contrataram a empresa Profill Engenharia e Ambiente para a 
elaboração do EIA e o RIMA. Os empreendedores contratantes propõem, segundo o RIMA (PROFILL, 2013c, p.07), a ocupação de cinco lotes de uso predominantemente residencial, totalizando 2.128 unidades residenciais de tipo unifamiliar, um lote destinado ao uso turístico/hoteleiro com oito economias, sete lotes destinados a instalação de áreas comerciais - totalizando 148 economias- e um polo tecnológico, somado a quatro lotes destinados ao uso institucional que não são computados no total geral de economias. Com a implementação completa do empreendimento, espera-se um crescimento na população local de cerca de 60\%, segundo o EIA (PROFILL, 2013a, p. 440).

Para a realização do projeto os empreendedores expõem várias argumentações, a primeira delas é que o empreendimento concordaria com as diretrizes de desenvolvimento urbanístico da cidade que priorizam o crescimento da zona sul. Esperam que sua proposta funcione como "contenção da expansão urbana em direção à Orla do Guaíba" (PROFILL, 2013b, p. 39) e que as áreas comerciais propostas se tornem um fator de desenvolvimento para a população residente. Sua expectativa é tornar a Fazenda "uma nova centralidade, atraindo moradores de outros bairros da Zona Sul de Porto Alegre, qualificando o Belém Novo e revitalizando a região" (PROFILL, 2013a, p. 448), isto devido segundo eles "ao grande potencial turístico e cultural" da Fazenda. Argumentam também que os bairros desta região "começaram a sofrer nos últimos anos a pressão da ocupação urbana intensiva" (PROFILL, 2013a, p. 271) e que no caso de não realizar o projeto, "haveria possibilidade de invasão na Fazenda, como outrora já ocorreu", segundo um dos engenheiros entrevistados por Oliveira (2017, p.39), quem adicionou que o empreendimento irá trazer a "geração de em torno de dois mil empregos" que, segundo ele, beneficiariam os moradores do bairro.

Os coletivos ambientalistas: Destacam-se o movimento Preserva Belém Novo (campanha Preserva Arado), o Coletivo Ambiente Crítico e as contribuições de vários pesquisadores. As principais razões de oposição aos empreendimentos tem a ver com o volume de aterro necessário, a mortalidade de fauna, o esquecimento da participação popular, o aumento desconsiderado das economias e uma aparente indução ao erro por parte dos empreendedores produto da alteração do Plano Diretor em 2015. ${ }^{4}$

A proximidade ao Lago Guaíba determina que o terreno seja plano e alagadiço, não idôneo para construir, justificando o primeiro dos argumentos dos ambientalistas. Porém, nesse caso a explicação inicial provém dos empreendedores mesmos: Por se tratar de uma área de cotas baixas está prevista a necessidade de "significativos volumes de aterro" (PROFILL, 2013a, p. 379). Estes volumes de terraplanagem "ainda não foram definidos, pois o projeto ainda está em andamento" (PROFILL, 2013a, p. 379). Contudo, segundo o Coletivo Ambiente Crítico, a exigência normativa é que as novas edificações devem estar numa elevação de 3,23m acima do Guaíba e isso implicaria um aterramento de 116 hectares de várzeas e banhados, somando mais de 1,5 milhões de metros cúbicos de terra, um fato que qualificam como "aterro monstruoso". Já foi exposta a função da Fazenda como corredor ecológico, constituindo o segundo argumento dos ambientalistas que advertem, baseados no EIA, que a implantação do empreendimento geraria "desde o deslocamento/afugentamento ao aumento da mortalidade da fauna" (OLIVEIRA, 2017, p. 41). Embora o empreendimento tenha previstas medidas de mitigação destes impactos, o mesmo EIA reconhece que estes são de natureza "negativa e irreversíveis".

Outro argumento dos coletivos é a falta da real participação da população impactada nas alterações normativas realizadas. Para eles, embora foi feita uma Audiência Pública para socializar o projeto e oferecer contrapartidas, esta não foi divulgada corretamente e não 
teve presença representativa da população, pois a maioria das pessoas eram funcionárias da Secretaria Municipal do Meio Ambiente (SMAM) e do empreendimento. Além disso, na Audiência não foi comunicado para a comunidade que haveria necessidade de mudar o PDDUA para a realização do empreendimento. $O$ resultado das alterações normativas foi um aumento exagerado das economias, que passou de 276 para 3664 economias, um aumento de $1230 \%$.

O último dos argumentos dos grupos Coletivo Ambiente Crítico e Preserva Belém Novo ${ }^{5}$ questiona a idoneidade tanto dos terrenos para ser construídos quanto dos mapas apresentados pelo EIA e retorna para o tema do caráter alagadiço da região. Como se observa na Figura 3, os mapas do EIA "induzem o leitor ao erro no que se refere à caracterização geológica da Fazenda" (OLIVEIRA, 2017, p.43), pois o EIA omitiu a presença do chamado "Sistema Laguna-Barreira IV" que abrange terrenos em "permanente transformação, sujeitos a inundações de rios e lagos, movimentação de dunas e subida de marés" (DOSSIÊ, 2016, apud OLIVEIRA, 2017, p.43). Para viabilizar o projeto, nos mapas do EIA indica-se somente a presença de "cordões arenosos"; conduzindo, "através de cores excessivamente parecidas, até mesmo o olhar técnico a concluir de maneira errada a natureza geológica do terreno em questão" (DOSSIÊ, 2016, apud OLIVEIRA, 2017, p.43).

Figura 3 - Sistema Laguna-Berreira IV

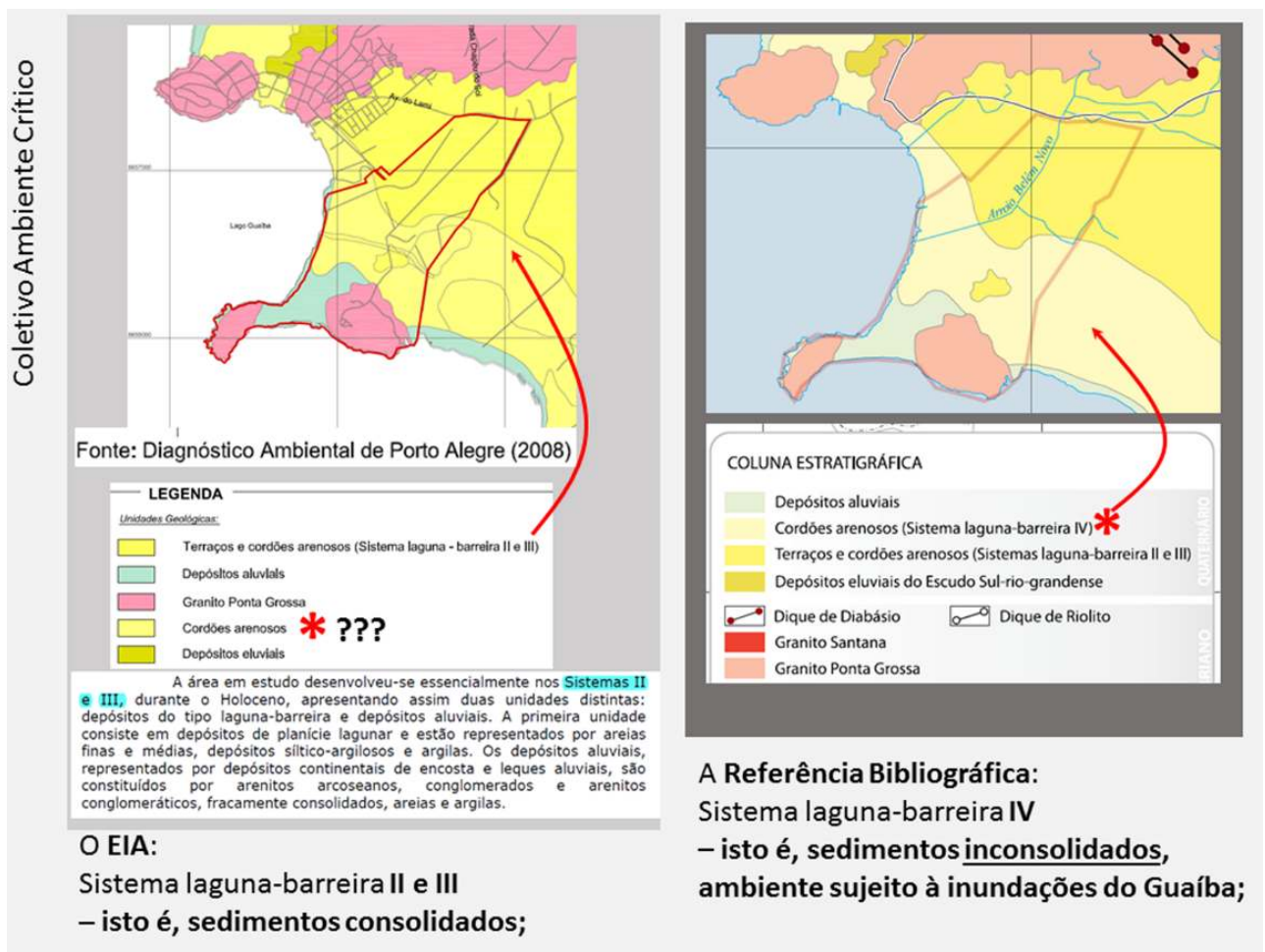

FONTE: FACEBOOK COLETIVO AMBIENTE CRÍtico, 2018.

A população do bairro Belém Novo: Talvez uma evidência da importância do seu papel na discussão é a forma como aparece no centro da divergência: Enquanto para os empreendedores os moradores do bairro têm sido incluídos no processo, para os coletivos ambientalistas a população não tem tido uma real participação na tomada de decisões. A opinião da população destaca pela sua ausência. Das narrações de Oliveira (2017) se deduz que existem uma série de contrapartidas oferecidas pelos responsáveis dos 
empreendimentos que, segundo eles, foram negociadas com a comunidade. Mas a vontade da população parece ser diferente, segundo algumas impressões obtidas das pesquisas de Oliveira (2017), nas quais um morador afirma, por exemplo, que "parte da população local vem apresentando reiteradas vezes seu descontentamento com a construção de condomínios de casas de luxo no bairro" (OLIVEIRA, 2017, p.46), fazendo referência explícita a um dos últimos condomínios fechados construídos na região, o Terraville. Em relação a este condomínio, outro morador afirmou: "cara, o Terraville até hoje não trouxe benefício nenhum para nós. $O$ pessoal do Terraville não compra aqui, compra fora daqui" (PRESERVA BELÉM NOVO, 2016, apud OLIVEIRA, 2017, p.47). Em aparência trata-se de dois tipos de população bem diferentes, pois para os moradores tradicionais do bairro, o pessoal de Terraville "não participa da vida ativa do bairro" (PRESERVA BELÉM NOVO, 2016, apud OLIVEIRA, 2017, p.47).

o Estado: Devido aos diferentes "rostos" que pode mostrar o Estado através das instituições, seu papel poderia-se qualificar como ambivalente, prova disso são as alterações normativas já referidas que geram sérias dúvidas frente a transparência da relação entre o Estado e os empreendedores. Um dos espaços mais representativos para entender a ambivalência do Estado é a Câmara Municipal de Vereadores de Porto Alegre, cujas decisões não se têm apresentado de maneira totalmente clara pela simples sucessão dos fatos, evidenciando que apesar de estar em aparência do lado dos empreendedores, no seu interior ficaram vozes de oposição ao projeto. É interessante mencionar algumas delas a partir de Oliveira (2017):

'Nunca vi sustentabilidade que prevê uma área de asfalto. Independentemente do projeto, aquela é uma área que deveria ser preservada'. Parte dos vereadores afirmou que haveria um 'poder das construtoras sobre o Legislativo', e um vereador provocando seus demais colegas afirmou: 'a população pode pensar que vossas excelências receberam dinheiro de empreiteiras. Os senhores deveriam se sentir impedidos moralmente de votar esse projeto' (HICKMANN, 2015, apud OLIVEIRA, 2017, p.53)

Outra voz que reforça a ambivalência do Estado é o conceito de um Grupo de Trabalho da Secretaria de Cultura de Porto Alegre que argumenta que a Fazenda do Arado tem potencialidade para ser um bem patrimonial devido à existência de bens arqueológicos relacionados com a etnia Guarani. A ideia deles é que "esta área pode ser percebida enquanto o que chama de Paisagem Cultural, na qual entende-se a paisagem associada à história dos lugares e suas significâncias" (TOCHETTO, et. al. 2013, apud OLIVEIRA, 2017, p.54). De fato, expõe Oliveira (2017) citando a professora Patrícia Gaulier (2001-2002) que os fragmentos cerâmicos encontrados são suficientes para evidenciar a ocupação da etnia e por isso a área foi delimitada como sitio arqueológico.

Até aqui se tem analisado a paisagem para obter um panorama geral do "campo de batalha". Conferindo a definição proposta de "paisagem" e "gestão da paisagem" não se tem encontrado um processo harmônico, e ao contrário, acredita-se pelas evidências expostas, que os responsáveis dos empreendimentos na Fazenda do Arado têm assumido o papel de gestores da paisagem quase por completo. Na sequência, vai se associar a problemática em questão dentro de um contexto mais amplo para entender os fatos e o papel da paisagem na luta percebida. 


\section{A utilização especulativa da paisagem, a ofensiva da urbanização capitalista.}

33 A gestão da paisagem e os processos de urbanização têm uma relação íntima. É paisagem tanto um território sem urbanizar ou levemente urbanizado quanto um território urbanizado com alta densidade e, na medida que isso acontece, começa-se a falar de paisagem urbana. Segundo Ferrer (2009) a qualidade da paisagem urbana se tem tornado um elemento cada vez mais significativo na valoração dos resultados da ação urbanística, pois "a cidade, entendida como entorno físico construído para a vida social, pode ser enxergada, ou imaginada, como paisagem" (FERRER, 2009, p.41). Nesse contexto, o projeto de cidade - ou de paisagem urbana - deve ter controle das atuações sobre os elementos que compõem o espaço urbano, isto é, administrar de maneira sistêmica os elementos comuns da urbanização e, pela natureza da atividade urbanística; a gestão do solo, dos seus usos e do seu mercado, são essenciais na consecução de uma paisagem urbana de qualidade.

Porém, a gestão da paisagem urbana não tem sido uma tarefa fácil. Os processos económicos, sociais e culturais, além das mudanças tecnológicas especialmente durante o século passado; geraram a expansão das cidades e obrigaram ao ser humano a abranger cada vez mais uma parte maior do território. Para deslocar-se passou dos cavalos aos trens, até finalmente domesticar o território deslocando-se de carro a qualquer parte. Os limites das cidades se apagaram e estas se tornaram metrópoles. A paisagem urbana tornou-se metropolitana, uma paisagem sem dúvida difusa, "até o ponto de não dar resposta à pergunta sobre onde começa e termina o mundo metropolitano" (FERRER, 2009, p.62). Nessa contínua necessidade de ampliar os limites urbanos se enraíza a dificuldade para a gestão da paisagem metropolitana.

Mas compreender a mudança de cidade a metrópole e dos seus impactos sobre a paisagem não é um fato simples e por isso é motivo de estudo de várias disciplinas. Grande parte dos teóricos sobre o tema coincide em atribuir a origem dessa mudança à crise do fordismo. Em poucas palavras, poder-se-ia dizer que quando o ser humano alcançou os limites da sobreprodução de objetos próprios da acumulação capitalista, esse sistema econômico encontrou nos processos de urbanização uma saída à crise que ele mesmo tinha gerado, puxado por uma dinâmica globalizada e informacionalizada.

36 A situação que se tem encontrado na Fazenda do Arado, em relação às intenções para a realização de um desenvolvimento urbanístico, tem relação direta com a configuração de Porto Alegre como área metropolitana. Por isso é pertinente ampliar a ideia do parágrafo anterior e baseado vários autores, associar esta problemática com as tendências constitutivas metropolitanas e de maneira particular com as mudanças que estão acontecendo nas cidades latino-americanas. De Mattos (2006) propõe cinco tendências: a cidade policêntrica, a cidade informal, a cidade negócio, a cidade do automóvel e a cidade artefato. Villegas et al. (2017a) acrescentam mais três: a cidade esbanjada, a cidade sem memória e a cidade orquestrada. Um breve percurso pelos conceitos dessas tendências permitiria conferir até que ponto Porto Alegre, no contexto da luta apresentada, está percorrendo essa trilha enquanto se consolida como Área Metropolitana.

37 A cidade policêntrica faz referência à aparição de novas empresas de qualquer parte do mundo que devido aos tratados de livre comércio conseguem entrar e gerar novos centros 
de atividade, em qualquer parte de qualquer cidade. A cidade informal se configura no contexto mesmo das políticas de desregulação e liberalização da economia que criam condições de desigualdade para as populações locais e aumentam o desemprego e os trabalhos instáveis, enquanto deslocam os mais pobres para as periferias. A cidade negócio tem a ver com a proliferação dos mercados imobiliários e com a exacerbação da indústria da construção, uma dinâmica que persegue o proveito do mais-valor urbano: é a queda do fordismo e a ascensão da indústria da construção. Na cidade do automóvel a explosão da mobilidade urbana é produto da aparição dessas novas empresas que produzem processos de periurbanizaçao e cidades projetadas para os carros e não para as pessoas.

A cidade artefato descreve a aparição massiva de "ícones urbanos": grandes edifícios como hotéis, centros comerciais e complexos empresariais que devido a estratégias de city marketing próprias do mundo globalizado dividem o espaço urbano em "cidade para mostrar" e "cidade para esconder". A cidade esbanjada está caracterizada pelo aumento do consumismo e pelos impactos ambientais irreversíveis produzidos pelos processos acelerados de construção, pela geração de "ilhas de calor" e pela multiplicação de comunidades locais que assumem as externalidades da urbanização capitalista; essa prática que percebe "a ecologia como uma convidada inoportuna no grande banquete da economia global” (VERDAGUER, 2014, p.2). A cidade sem memória tem a ver com a degradação dos centros tradicionais e apresenta-se como a soma das anteriores tendências: o centro histórico como mais um centro da cidade policéntrica, um lugar exposto à informalidade pois todo dia recebe milhares de pessoas que trabalham nas ruas. É também objetivo dos negócios imobiliários através de projetos de renovação urbana ${ }^{6}$, além de sofrer de graves problemas de tráfego veicular e poluição.

Encerrando o viés da constituição das metrópoles se apresenta a cidade "orquestrada", uma tendência em aparência imperceptível, pois em comparação com as demais, esta é mais difícil de verificar na geografia física da cidade, devido a que está relacionada com as mudanças no nível institucional. É uma metáfora que busca explicar a mudança das funções do Estado de uma agenda administrativa para uma agenda empresarial, no marco da financeirização global. É a "sinfonia" urbanística executada conjuntamente entre o Estado e os grandes capitais, onde em coerência com a metáfora, o Estado tem cedido o poder de orquestração para ficar com o poder de instrumentação. A orquestração referese a quem escreve as partituras e dirige a execução -o grande capital-, enquanto a instrumentação é exercida por quem viabiliza as decisões -o Estado-, embora este mantém a sensação de estar agindo com autonomia. Aqui se faz uma rápida verificação sobre o caso da Fazenda do Arado em palavras de um dos ambientalistas entrevistado por Oliveira (2017, p.48):

Haveria uma nítida relação espúria entre o Estado e o consórcio interessado em construir o empreendimento na Fazenda do Arado. Isso se constata através da simples sucessão dos fatos, à medida que poucas semanas depois da aprovação do retorno da Zona Rural o executivo envia um projeto de lei que altera o regime urbanístico exatamente nas limitações da propriedade do empreendedor e é aprovado.

Conferindo as tendências é muito possível encontrar que Porto Alegre - e a problemática da Fazenda - encaixa perfeitamente, se não em todas, na maioria das tendências expostas. Isso explica em grande parte o porquê das lutas pela urbanização das periferias, entendendo que nos processos de formação das metrópoles, os mais pobres são obrigados pelos interesses dos grandes capitais a procurar solo nos lugares mais afastados, enquanto 
os negócios imobiliários, da mão do Estado produzindo para eles mais solo urbano, tiram proveito dos ambientes com riquezas naturais. Esta prática justifica a expressão "utilização especulativa da paisagem" e já verificada nos acontecimentos da Fazenda do Arado, permite entender que é efetivamente uma ofensiva da urbanização capitalista.

Mas o caso da Fazenda traz ainda mais outro componente. Além de se localizar na periferia da cidade, a Fazenda está na orla do lago Guaíba, e isso parece atrair muito mais os interesses especulativos capitalistas. As condições paisagísticas das costas e das bordas dos corpos de agua têm-se tornado nos últimos anos um cenário idôneo para a especulação e para a realização de grandes empreendimentos imobiliários. 0 tema é amplamente exposto por Hidalgo et al. (2016) quem mostra que esse tipo de especulação mercantil é muito suscetível de se tornar degradação ambiental, relacionando através de vários exemplos essa "destruição criativa da natureza" com os efeitos das políticas neoliberais na América do Sul. $\mathrm{O}$ autor questiona a forma como as bordas das costas, que geralmente são entendidas como bens comuns, terminam sendo apropriadas para a construção de condomínios fechados, uma prática que confronta em palavras dos autores "o ideal de justiça espacial e a iniquidade territorial" e que infelizmente abrange também as bordas dos rios e lagos.

Existem ao redor do mundo vários exemplos da utilização especulativa da paisagem através da exploração de regiões próximas dos corpos de água. Se poderiam mencionar alguns como o caso de Bilbao (Espanha) e o de Buenos Aires (Argentina); duas estratégias similares, mas com diferentes modus operandi. Segundo Martinez (2014) em Bilbao, com o objetivo de recuperar a paisagem urbana ao longo da $\mathrm{Ria}^{7}$, se construiu o Museu Guggenheim como um artefato para vender a cidade. Este gerou um sucesso turístico que logo trouxe a construção de novos ícones que saturaram a paisagem urbana, gerando críticas devido aos impactos sócio espaciais: a região tornou-se uma das mais caras para morar e se evidenciou a falta de participação popular.

Em Buenos Aires, segundo Cuenya e Corral (2011), o solo de Puerto Madero e das áreas próximas do Rio de La Plata experimentaram a mudança dos usos e a comercialização de terras públicas a partir da atração do investimento privado de lógica especulativa. Isto aconteceu através da criação de uma empresa urbanizadora estadual que esteve presente em todas as atividades relacionadas com a construção, da projetação até a comercialização. Na prática foi um solo ator exercendo a gestão da paisagem, explorando e especulando por causa da presença do corpo de agua.

Sobre estas práticas especulativas com os bens imóveis, segundo Smith (2012), um dos mecanismos utilizados pelos atores da urbanização capitalista para especular é a criação da chamada renda diferencial - rent gap-, que consiste em gerar uma lacuna entre os preços dos bens existentes em uma região determinada (solo, estruturas construídas, alugueis) e os preços das novas estruturas urbanas que começam aparecer. Enquanto aquilo que existe perde valor de troca, aquilo que está por aparecer aumenta sem controle; como já aconteceu em referência ao Bairro Belém Novo e o mencionado condomínio Terraville, cujo modelo quebrou os preços imobiliários da região. Isto mesmo parece acontecer na dinâmica entre o Bairro Belém Novo e a Fazenda do Arado, área idônea para a especulação capitalista. 


\section{A construção do conceito de paisagem local, a defesa da técnica e do coletivo}

Diante da problemática exposta e em coerência com as definições apresentadas inicialmente tanto de "paisagem" quanto de "gestão da paisagem", é necessário contrapor o viés do desenvolvimento identificado na Fazenda do Arado à noção de paisagem local, isto é, coletar instrumentos que se afastem de perseguir só os objetivos dos grandes capitais -para o caso, os empreendedores-; para passar a valorizar a comunidade local e as características do território, envolvendo os outros atores no processo de gestão e equilibrando assim as condições da luta. $O$ conceito procurado tem a ver com essa visão referida inicialmente como coletiva e participativa, técnica e transdisciplinar; como vai se expor na sequência.

Embora o processo de gestão da paisagem passa pela expressão dos seus componentes em mapas e desenhos, está longe de ser um elemento puramente visual. O procedimento habitual dos empreendedores é chegar até as comunidades com projetos já elaborados e tentar, através de recursos visuais, socializar suas intenções só para responder exigências normativas, como parece ter acontecido com as Audiências Públicas no caso da Fazenda do Arado. Em contraposição, o CEP (2000) concebe a gestão da paisagem como um processo em cujas fases insistem de maneira permanente na participação dos atores sociais, no estabelecimento de consensos, na realização de entrevistas e no exercício de uma liderança participativa por parte dos promotores. 0 protagonismo no processo deve ser da sociedade -o coletivo-, que deve estar informada das propostas, mas também participar da elaboração delas. Para conseguir esse processo coletivo, insistem também na importância da constituição de fundos públicos e privados para a execução das propostas, além de fortalecer a educação em paisagem para que qualquer pessoa saiba o seu papel no processo.

47 Os EIA não podem ficar como mais uma exigência normativa e tampouco ser adaptados segundo os interesses dos empreendedores. Eles devem constituir a base técnica do processo de gestão da paisagem. Como foi exposto na fase de "Conhecimento e diagnose", para o caso da Fazenda existe uma grande vulnerabilidade ambiental que precisa de uma base técnica muito sólida, embora não se trata de uma especialização técnica sem limites. Nesse contexto, Santos (2006) critica "a extrema especialização do saber" e propõe encarar os problemas ambientais através de um "legítimo trabalho transdisciplinar" e de manter presente a evolução histórica do lugar, pois considera um risco se basear somente no presente. 0 convite de Santos é entender "a técnica como a base de realização da mundialidade como totalidade empírica" (SANTOS, 2006, p. 3), isto é, valorizar as experiências das diferentes técnicas como mecanismo para encarar os desafios de um mundo globalizado.

No processo de gestão da paisagem, os dados técnicos descrevem uma realidade que devese afrontar através do conhecimento acumulado pelo ser humano até conseguir "dominála e humaniza-la" (SANTOS, 2006, p.5). A técnica, pela sua inerência à realidade especifica de um lugar, deveria se consolidar como arma de defesa na luta contra os interesses capitalistas, que estão representados na busca de mais-valia em nível global através de forças produtivo-destrutivas, uma busca que é "apátrida, extraterritorial, indiferente às realidades locais ou, vamos dizer assim, às realidades ambientais" (SANTOS, 2006, p.9). 
Torna-se necessário no processo compor "metadisciplinas" que são a premissa do procurado trabalho transdisciplinar.

No conceito de paisagem local, a paisagem e sua gestão apresentam-se mais como construção sociocultural e não como imposição do mercado imobiliário, uma ideia defendida por vários autores, entre eles Paquette et al. (2005). Segundo eles, as comunidades já não aceitam só trafegar pelas suas paisagens, senão que estão reclamando uma função mais ativa na sua transformação e fundamentam seu argumento no fato da existência de documentos legais, programas políticos e iniciativas de planejamento que consideram o tema da paisagem. Em síntese, se propõe repensar a abordagem tradicional da paisagem como recurso visual nas mãos dos expertos, para começar a pensá-la à luz das preocupações sociais que a desafiam.

Poderia-se dizer então que uma paisagem de qualidade vai se conseguir na medida de obter sincronia entre os interesses da sociedade e o trabalho dos expertos. Mas nesse contexto transdisciplinar existem algumas disciplinas mais determinantes e poderia-se fazer um percurso através delas, com ciência de que a lista se deve adaptar às necessidades específicas, segundo expõem Busquets e Cortina (2009): Paisagistas ordenando tanto espaços abertos quanto construídos, arquitetos concebendo o espaço e geógrafos encarando a análise territorial. Ambientólogos, ecólogos e biólogos compreendendo os ecossistemas e gerando critérios de sustentabilidade, engenheiros aconselhando sobre a projetação de infraestruturas e urbanistas definindo os usos do solo.

51 Comparecem também juristas redigindo a "cartografia legal do território", gestores do patrimônio cultural como arqueólogos e antropólogos fomentando atividades como o turismo ou a formação. Outro grupo importante são os sociólogos e politólogos identificando os atores sociais e estabelecendo consensos. Consideram-se também os gestores turísticos ligando o "capital paisagístico" com as atividades de lazer e os agrônomos formulando planos técnicos para o manejo da flora. Educadores em paisagem fazendo sensibilização social e economistas procurando viabilidade econômica e financeira. Por último, fazendo ênfase na visão participativa, comparecem os psicólogos e os expertos em comunicação entendendo a percepção dos indivíduos apoiados pelos professionais das artes como fotógrafos e artistas plásticos.

Para o caso de estudo, a construção do conceito de paisagem local como uma visão alternativa aos limites e formas de ação propostos pelos empreendimentos, poderia considerar as unidades de paisagem identificadas: o bairro, a Fazenda e a orla. Estas unidades se poderiam utilizar para definir áreas de proteção, com possibilidades específicas de intervenção. Visto assim, a orla, ainda tendo grande parte como propriedade privada, poderia ter uma utilização mais coerente com as características do entorno e menos ligada aos interesses especulativos, entendendo que uma linha no mapa não define realmente a condição rural ou urbana de um local. Uma proposta específica de unidades da paisagem da fazenda se poderia construir em conjunto desde a base da comunidade local, com a participação administrativa do Estado e o apoio dos empreendedores privados.

53 A estrutura participativa da gestão da paisagem local tem relação com a ideia de governança e esta poderia ser um fundamento sólido. Um viés fundamental da governança é avançar para as relações mais dialógicas entre o Estado, os cidadãos e o mercado econômico, agindo na consolidação do desenvolvimento social, econômico e institucional. Este viés articula o conceito de governança com diferentes disciplinas, como 
a economia, a ciência política e a administração; desta última Farinós (2008) define a governança segundo seu objetivo: tornar a gestão dos assuntos públicos um exercício de inclusão e corresponsabilidade para superar modelos de gestão tributária de cima para baixo, centralizados e burocratizados. A inclusão implica incentivar o surgimento e a recepção de novos atores fora do espectro político.

Healy (1997) relaciona governança com "planejamento colaborativo", esclarecendo que se trata de planejar e gerenciar dinâmicas territoriais compartilhadas, isto é, baseadas em relações de negociação e consenso entre uma multiplicidade de atores que conseguiram um acordo sobre alguns objetivos, assumindo o compromisso de aplicar todo o seu potencial para alcançá-los. Na ideia de Healy, a governança obtém uma estrutura para seu exercício: trata-se do território no qual se institucionaliza uma prática de acordo social entre diferentes atores - pacto sócio territorial - para se chegar a um acordo sobre, por exemplo, uma gestão estratégica da paisagem, procurando um desenvolvimento da região com participação democrática da sociedade.

\section{Considerações finais}

Ao caracterizar a paisagem da Fazenda do Arado com rigor técnico se desvendam a falta de idoneidade dos terrenos para ser construídos, a presença de uma marca histórica, arquitetônica, arqueológica e cultural; além de uma vulnerabilidade ecossistêmica. Desvenda-se também uma questionável parceria entre os empreendedores e as instituições do Estado e o esquecimento das qualidades dos moradores atuais. Em uma escala maior, a problemática encontrada encaixa com as tendências constitutivas das metrópoles latino-americanas que mostram que o desenvolvimento imobiliário está guiado por uma visão mercantilista e especulativa da paisagem, próprias da urbanização capitalista e das exigências do mundo globalizado, que não se resistem às tentações das riquezas naturais das paisagens próximas aos corpos de água.

É obvio que a cidade deve procurar alternativas de desenvolvimento econômico para melhorar as condições da população, mas qual é o custo que deveria estar disposta a pagar por isso? Será realmente justificável sacrificar o patrimônio natural e histórico para aumentar os zeros das contas bancarias dos grupos econômicos mais poderosos? A busca deveria visar mais para um desenvolvimento mais justo, e por isso, apresenta-se como urgente repensar os processos de gestão da paisagem dando protagonismo à sociedade e recuperando o respeito pela técnica, através da configuração de uma base sólida entre as comunidades locais e as instituições do governo que orientem as ações dos investidores.

Tal vez um dos grandes erros no caso da Fazenda do Arado é o mencionado por Santos (2006): se está trabalhando somente no presente, esquecendo as dinâmicas urbanas previas. $O$ bairro foi primeira opção de moradia para um pessoal pobre e espaço de lazer para a cidade. Terminando o século XX os empreendedores imobiliários introduziram o conceito de condomínio horizontal fechado como forma de urbanizar e, na prática, assumiram a função de planejadores urbanos: um monopólio na gestão da paisagem. As expectativas de novos empreendimentos trouxe um aumento sem controle nos preços dos imóveis, configurando uma advertência clara sobre o fim especulativo que teria a paisagem da Fazenda do Arado e sobre a luta que foi analisada neste artigo. 


\section{BIBLIOGRAFIA}

BUSQUETS, J.; CORTINA, A. Gestión del paisaje. Manual de protección, gestión y ordenación del paisaje. Barcelona: Ariel, 2009.

CEP. Convênio Europeu da Paisagem. Florença: Conselho da Europa, 2000. Disponível em: <http:// www.upv.es/contenidos/CAMUNISO/info/U0670786.pdf>. Acesso em: maio 2018.

CUENYA, B.; CORRAL, M. Empresarialismo, economía del suelo y grandes proyectos urbanos: el modelo de Puerto Madero en Buenos Aires. EURE, Buenos Aires, vol. 37, №111, p.25-45, maio 2011. Disponível em: <https://scielo.conicyt.cl/scielo.php? pid=S0250-71612011000200002\&script=sci_arttext>. Acesso em: maio 2018.

DE MATTOS, Carlos. Modernización capitalista y transformación metropolitana en América Latina: cinco tendencias constitutivas. In: Geraiges de Lemos, A. et al. (org.). América Latina: cidade, campo e turismo. Buenos Aires: CLACSO, 2006. p. 41-74.

FARINÓS, Joaquín. Gobernanza territorial para el desarrollo sostenible: estado de la cuestión y agenda. BAGE, n. 46, 2008. p. $11-32$.

FERRER, Amador. Paisajes urbanos. In: BUSQUETS, J.; CORTINA, A. (org.). In: Gestión del paisaje. Manual de protección, gestión y ordenación del paisaje. Barcelona: Ariel, 2009. p. 41-60.

HEALY, Patsi. Colaborative Planning: Shaping place in fragmented Societies. Londres: UCL Press, 1997.

HIDALGO, R. et al. En las Costas del Neoliberalismo. Naturaleza, urbanización y producción inmobiliaria: experiencias en Chile y Argentina. Santiago: Pontificia Universidad Católica de Chile, 2016.

MARONEZE, Clarissa. Ver o presente, revelar o passado e pensar o futuro: A evolução urbana do bairro Belém Novo em Porto Alegre. 2017. Dissertação (Mestrado em Planejamento Urbano e Regional), Universidade Federal do Rio Grande do Sul, Porto Alegre, RS.

MARTINEZ, Alona. Impactos socio-espaciales de los grandes proyectos urbanos. Bilbao y su aplicabilidad a otras ciudades. Bitácora Urbano-Territorial, Bogotá D.C., vol. 1, N²4, p. 119-124, janeiro - junio 2014. Disponível em: <https://dialnet.unirioja.es/servlet/articulo?codigo=5001817 >. Acesso em: maio 2018.

OLIVEIRA, Joana de. A Fazenda do Arado: Conflito Ambiental e Ruralidade Contemporânea na Zona Sul de Porto Alegre. 2017. Dissertação (Graduação em Ciências Sociais), Instituto de Filosofia e Ciências Humanas, Universidade Federal do Rio Grande do Sul, Porto Alegre, RS.

PAQUETTE, S. et al. Le paysage, une qualification socioculturelle du territoire. Revue de la culture matérielle, vol. 62, p.60-72, 2005.

PROFILL. Estudo de Impacto Ambiental - EIA, vol. I. Porto Alegre - RS, dezembro 2013a. Estudo de Impacto Ambiental - EIA, vol. II. Porto Alegre - RS, dezembro 2013 b. . Relatório de Impacto Ambiental - RIMA. Porto Alegre - RS, dezembro 2013c. 
SANTOS, Milton. A questão do meio ambiente: desafios para a construção de uma perspectiva transdisciplinar. Revista da Gestão Integrada em Saúde do Trabalho e Meio Ambiente, São Paulo, vol. $1, \mathrm{~N}^{\circ} 1,2006$.

SMITH, Neil. La nueva frontera urbana. Ciudad revanchista y gentrificación. Madrid: Traficantes de sueños, 2012.

VERDAGUER, Carlos. Paisaje antes de la batalla. Boletín CF+ S, N¹3, 2014. Disponível em: <http:// polired.upm.es/index.php/boletincfs/article/view/2616/2682>. Acesso em: jun. 2017

VILLEGAS, G. et al. De ciudad a región metropolitana. Referentes conceptuales y críticos para interpretar el cambio.Virajes, Manizales, vol. 19, N² , p.115-137, jul - dez 2017a. Disponível em: < http://vip.ucaldas.edu.co/virajes/downloads/Virajes19(2)_7.pdf>.

. Renovación urbana del centro histórico de Bogotá D.C. (Colombia). Del barrio santa Bárbara al Bronx, un legado de desplazamiento y gentrificación. Geografares, Vitória, №24, p.97-117, 2017b. Disponível em: <http://www.portaldepublicacoes.ufes.br/geografares/article/ view/17954>.

\section{NOTAS}

1. Mencionam-se alguns, segundo o próprio convênio (Conselho da Europa, 2000): a Convenção sobre a conservação da vida selvagem e meio ambiente natural na Europa (Berna, 1979), a Convenção para a salvaguarda do patrimônio arquitetônico da Europa (Granada, 1985), a Convenção europeia para a proteção do património arqueológico (Valletta, 1992), a Convenção europeia sobre a cooperação transfronteiriça entre comunidades ou autoridades territoriais (Madrid, 1980), a Carta europeia do autogoverno local (Estrasburgo, 1985), a Convenção sobre a diversidade biológica (Rio de Janeiro, 1992), a Convenção sobre o proteção do património mundial, cultural e natural (Paris, 1972) e a Convenção sobre o Acesso à Informação, a participação do público na tomada de decisões e no acesso à justiça em questões ambientais (Aarhus, 1998).

2. Encontrou-se uma espécie mamífera "vulnerável" - o Gato Maracajá -, uma espécie ameaçada de extinção no estado - o Bugio-ruivo - e outra espécie de interesse especial em conservação, o Rato-da-Taquara.

3. As aspas fazem referência a uma série de questionamentos encontrados na forma que as contrapartidas foram oferecidas e negociadas com a comunidade.

4. A alteração foi descrita nos aspectos normativos que fazem parte das fontes de informação indireta.

5. Oliveira (2017) esclarece que esses análises contaram com o apoio da ONG Ingá, o Instituto Econsciência e do professor Rualdo Menegat.

6. Um exemplo interessante que desvenda a participação de vários atores no processo de renovação urbana do centro histórico de Bogotá D.C. pode ser encontrado em Villegas et al. (2017b).

7. Se chama "Ria" um corpo de água salgada que entra no continente. 


\section{RESUMOS}

Este artigo analisa o caso da problemática urbana na Fazenda do Arado em Porto Alegre (RS Brasil). O estudo da paisagem orienta o roteiro metodológico para a compreensão de um enfrentamento: de um lado os interesses urbanizadores de empreendedores privados e no lado oposto as características do entorno, a idoneidade dos terrenos e as percepções da cidadania. Percebe-se uma luta socioespacial e para entendê-la, primeiro se esclarecem "as regras do jogo" definindo os conceitos de "paisagem" e "gestão da paisagem". Posteriormente caracteriza-se o "campo de batalha" através de uma análise da paisagem que desvenda sua possível utilização especulativa, qualidade que logo se apresenta como "a ofensiva da urbanização capitalista", em um exercício de associação com as tendências constitutivas das metrópoles latino-americanas. A luta se contrapõe à construção do conceito de paisagem local como "estratégia de defesa" baseada no rigor da técnica e na abrangência do que é coletivo e guiada por uma visão transdisciplinar como alternativa para encarar os desafios do mundo globalizado.

Cet article analyse le cas de problèmes urbains dans la Fazenda do Arado à Porto Alegre (RS Brésil). L'étude du paysage guide l'itinéraire méthodologique pour la compréhension d'une confrontation: D'une part, les intérêts urbanisant des promoteurs privés et, d'autre part, les caractéristiques de l'environnement, la pertinence du territoire et les perceptions des citoyens. Une lutte socio-spatiale est perçue et pour la comprendre, les «règles du jeu» sont d'abord clarifiées lors de la définition des concepts de "paysage" et de "gestion du paysage". Plus tard, le "champ de bataille" est caractérisé par une analyse du paysage qui révèle son utilisation spéculative, caractéristique présentée ici comme "l'offensive de l'urbanisation capitaliste", dans un exercice d'association avec les tendances constitutives des métropoles latino-américaines. La lutte s'oppose à la construction du concept de paysage local en tant que "stratégie de défense" basée sur la rigueur de la technique et de la portée du collectif et guidée par une vision interdisciplinaire comme alternative aux défis du monde globalisé.

Este artículo analiza el caso de la problemática urbana en la Fazenda do Arado en Porto Alegre (RS - Brasil). El estudio del paisaje orienta la ruta metodológica para la comprensión de un enfrentamiento: en un lado los intereses urbanizadores de promotores privados y en el otro las características del entorno, la idoneidad de los terrenos y las percepciones ciudadanas. Se percibe una lucha socioespacial y para entenderla, primero se aclaran "las reglas del juego" al definir los conceptos de "paisaje" y "gestión del paisaje". Posteriormente se caracteriza el "campo de batalla" a través de un análisis del paisaje que revela su utilización especulativa, rasgo que aquí se presenta como "la ofensiva de la urbanización capitalista", en un ejercicio de asociación con las tendencias constitutivas de las metrópolis latinoamericanas. La lucha se contrapone a la construcción del concepto de paisaje local como una "estrategia de defensa" basada en el rigor de la técnica y en el alcance de lo colectivo y guiada por una visión interdisciplinar como alternativa para enfrentar los desafíos del mundo globalizado.

This paper analyzes the case of the urban problems of the Fazenda do Arado in Porto Alegre (RS Brazil). The study of the landscape proposes the methodological route for understanding a confrontation: On one side are the interests of private developers while on the opposite side are the environmental characteristics, the land suitability and the citizenship perceptions. A socio- 
spatial struggle is perceived and to understand it, first the "rules of the game" are clarified with the definition of "landscape" and "landscape management" concepts. Then the "battlefield" is characterized trough a landscape analysis that reveals its possible speculative use, a feature that is shown as "the capitalist urbanization offensive" in an exercise of association with the constitutive tendencies of Latin American metropolis. The struggle is contrasted with the construction of local landscape concept as a "defense strategy" based on the accuracy of the technique and on the reach of what is collective, guided by an interdisciplinary approach as an alternative to face the challenges of the globalized world.

\section{ÍNDICE}

Mots-clés: Étude de paysage, urbanisation capitaliste, tendances métropolitaines, vision interdisciplinaire, spéculation urbaine.

Palavras-chave: Estudo da paisagem; urbanização capitalista; tendências metropolitanas; visão transdisciplinar; especulação urbana.

Palabras claves: Estudio del paisaje, urbanización capitalista, tendencias metropolitanas, visión interdisciplinar, especulación urbana.

Keywords: landscape study, capitalist urbanization, metropolitan tendencies, interdisciplinary approach, urban speculation.

\section{AUTOR}

\section{JUAN GUILLERMO VILLEGAS.}

Mestrando do Programa de Pós-graduação em Geografia UFRGS.

E-mail: villegasjg@gmail.com 